\title{
Kernos
}

Revue internationale et pluridisciplinaire de religion grecque antique

$8 \mid 1995$

Varia

\section{Papadopoulou-Belmehdi, Le chant de Pénélope. Poétique du tissage féminin dans l'Odyssée}

\section{Vinciane Pirenne-Delforge}

\section{(2) OpenEdition \\ Journals}

Édition électronique

URL : http://journals.openedition.org/kernos/625

DOI : $10.4000 /$ kernos. 625

ISSN : 2034-7871

Éditeur

Centre international d'étude de la religion grecque antique

Édition imprimée

Date de publication : 1 janvier 1995

Pagination : 321-322

ISSN : 0776-3824

Référence électronique

Vinciane Pirenne-Delforge, «I. Papadopoulou-Belmehdi, Le chant de Pénélope. Poétique du tissage féminin dans l'Odyssée », Kernos [En ligne], 8| 1995, mis en ligne le 12 avril 2011, consulté le 24 septembre 2020. URL : http://journals.openedition.org/kernos/625 ; DOI : https://doi.org/10.4000/ kernos.625 
de gamelia; il aurait fallu, fût-ce en note, évoquer l'ambiguïté des sources qui parlent aussi d'un sacrifice émanant du père pour sa fille avant le mariage (Pollux, VIII, 107); - dans la bibliographie, on peut déplorer l'absence de quelques titres utiles sur le thème: A. Avagianou, Sacred Marriage in the RItuals of Greek Religion, Bern, 1991, P. Brulé, La fille d'Athènes, Paris, 1987 et Cl. CALAME, Les chœurs de jeunes filles en Grèce archaïque, Urbino, 1977. Pour évaluer le rôle d'Aphrodite dans les mariages, qu'on me permette de renvoyer aujourd'hui à mon ouvrage L'Apbrodite grecque, Kernos Supplément 4 (1994).

Vinciane PIRENNE-DELFORGE (Université de Liège)

Ioanna Papadopoulou-Belmehd, Le chant de Pénélope. Poétique du tissage féminin dans l'Odyssée, Préface de Nicole Loraux, Paris, Belin, 1994. 1 vol. $14 \times 20,5 \mathrm{~cm}, 224$ p. (L'Antiquité au Présent). ISBN : 2-70111764-X. Prix : 125 FF.

La gloire de son mérite ne périra jamais, et les immortels composeront pour les humains un chant charmant sur la sage Pénélope. Ainsi s'exprime le poète aux vers 196-198 du chant XXIV de l'Odyssée, justifiant en quelque sorte l'intérêt que porte aujourd'hui à la femme d'Ulysse Ioanna PapadopoulouBelmehdi. Ce n'est pas la première fois que Pénélope est étudiée, mais ce livre en donne assurément l'analyse la plus soucieuse de débusquer les prétendues incohérences du personnage et de rendre un sens à l'ensemble de ses apparitions dans le poème, sans recourir à des arguments extérieurs à lui.

En 13 chapitres qui courent en continu au travers de 4 parties ( $L$ 'Ithaque de Pénélope; Tisserandes de l'utopie; le rituel est poétique; Le tissage de la matière épique), l'A. nous présente l'équivalent féminin d'Ulysse le héros: Pénélope, la reine rusée qui, par les mouvements alternatifs du tissage et du détissage, va permettre à la mémoire du roi de survivre dans l'île d'Ithaque qui croit à sa mort obscure. Volontairement immobilisée dans le statut ambigu de la jeune fille adonnée aux travaux d'Athéna, la reine est un faux-semblant de vierge, elle qui tente de protéger son fils et attend le retour de son époux. Le refus du mariage avec l'un des prétendants n'est pas le signe de sa velléité mais celui de sa détermination. C'est grâce à elle et à son combat contre la perte de la mémoire qu'Ulysse pourra retrouver son identité et sa royauté, tout en fondant son kleos, sa gloire.

Le thème du tissage, très finement analysé par l'auteur, est ambivalent : d'un côté, il peut être utilisé comme métaphore de la fonction royale, de l'autre il est omniprésent dans ce monde irréel de personnages féminins que doit traverser Ulysse pour rentrer au foyer. Le tissage, associé à Pénélope la vú $\mu \varphi \eta$ tout autant qu'aux nymphes éternelles que sont Calypso, Circé, Nausicaa ou encore les déesses de la grotte en Ithaque, est le noud du passage d'un monde à l'autre, dans le dédale du parcours d'Ulysse autant que dans le palais intemporel parce que figé sur un problème matrimonial. 
Pénélope est donc l'expression de la mémoire en opposition, notamment, avec Calypso qui symbolise une immortalité porteuse d'oubli. La mémoire est compatible avec la survie du héros, ce qui différencie le message héroïque de l'Odyssée de celui de l'Iliade. Ulysse ramènera lui-même sa gloire au sortir de ses errances dans l'irréalité et de son passage dans l'au-delà, grâce à la vigilance de cette autre figure de métis qu'est Pénélope.

La toile de Pénélope devient ainsi « le code d'accès à la structure sinueuse de la poétique odysséenne » et Pénélope elle-même se définit en référence à ces personnages-penseurs, mis en lumière par Dodds, porteurs de la voix du poète.

Au terme de ce voyage - qui n'est pas sans rappeler parfois les sinuosités du parcours d'Ulysse, en dépit d'un style clair et élégant -, on regarde la reine d'Ithaque avec d'autres yeux; autour de sa toile se mêlent les thèmes du mariage, de la mort, de la métis, de la mémoire, de la royauté et de la gloire. Le livre de Ioanna Papadopoulou-Belmehdi donne l'envie de relire l'Odyssée et ce n'est pas le moindre de ses mérites.

Vinciane PIRENNE-DELFORGE

(Université de Liège)

Jean-Michel ReNaud, Le mytbe de Meléagre. Essais d'interprétation. Liège, 1993, 173 p. (disponible chez l'auteur, 37, rue Naimette, B - 4000 Liège)

Ce petit ouvrage, qui représente le mémoire de Licence de l'A., est une tentative d'interprétation globale du mythe de Méléagre, tel qu'il nous a été transmis par les sources antiques. Après un premier chapitre qui reconstitue l'ensemble du récit, avec ses nombreuses variantes, l'A. propose une analyse minutieuse de chacune des deux grandes parties qui le composent dans la plupart des textes : la chasse au sanglier et la guerre entre Étoliens et Courètes. Il tente ensuite de dégager la signification d'ensemble du mythe, en précisant la fonction des personnages qu'il met en jeu ainsi que l'arrière-plan divin qui éclaire leur comportement, et revient pour finir - en un ordre un peu surprenant -, sur le récit de Phénix, au chant IX de l'lliade.

Cette étude, conduite avec méthode et honnêteté, a pour mérite essentiel de prendre en compte toutes les données du mythe, en s'efforçant de rendre à chacune d'elles sa signification. On peut ne pas être toujours convaincu par les explications étymologiques proposées pour les noms des personnages, et trouver quelque peu réductrices certaines assimilations entre tel d'entre eux et telle ou telle divinité. Mais les propositions de lecture sont, dans l'ensemble, judicieuses et stimulantes, et l'on en retiendra, en particulier, l'interprétation de Méléagre comme celle d'un personnage qui, dominé par l'univers féminin, manque son initiation et ne parvient pas à s'intégrer véritablement dans le monde des hommes accomplis.

Christine MAUDUIT

(Université de Lyon II) 